\title{
Yolanda Queiroga de Assis: uma poética sob a égide da tristeza e do ressentimento
}

\author{
Olavo Barreto de Souza ${ }^{2}$ \\ José Hélder Pinheiro Alves ${ }^{3}$
}

\begin{abstract}
Resumo: A Crítica Literária na Paraíba tem realizado um trabalho tênue na produção de estudos sobre as mulheres escritoras deste estado. Sabemos que a Crítica tem um papel muito importante na divulgação de autores com visibilidade em consolidação. No caso das escritoras, e especificamente das poetisas, em âmbito nacional, observa-se o crescimento de muitos estudos sobre suas produções de forma a darem margem para a visibilidade dessas mulheres no campo acadêmico, bem como nos suplementos literários de ordem geral. Assim, o presente estudo tem por objetivo fazer algumas considerações sobre a poesia de Yolanda Queiroga de Assis, com o intuito de divulgar a obra da autora, além de proporcionar um meio para a documentação de sua expressividade literária, especificando suas nuanças estéticas e temáticas, sobretudo, no que diz respeito ao tema do ressentimento. Para tanto, no texto que segue, fazemos uso das considerações teóricas de Bastos (2012), Cortez e Rodrigues (2009), Kehl (2004) e outros, a fim de fundamentar a leitura que ora propomos.
\end{abstract}

Palavras-chave: Poetisas paraibanas; Literatura Contemporânea; Yolanda Queiroga de Assis.

\section{Yolanda Queiroga de Assis: a poetic under the argis of sadness and of resentment}

\begin{abstract}
A Literary Criticism in Paraíba has performed a tenuous production labor of research about women writers in this state. We know that the criticism has an important role in disseminating authors with visibility in consolidation. In case of writers, and in our case, women poets, nattionally, is observed the growth of many studies on their productions in order to give space to the visibility of these authors in the academic field as well as general literature. Thus, this study aims to make a few remarks about poetry Yolanda Queiroga de Assis, in order to publicize the work of the poetess, as well as providing a means for documenting her literary expression, specifying hers aesthetic and thematic nuances, particularly with regard to the subject resentment. Therefore, the text that follows, we base our research on the theoretical considerations of Bastos (2012), Cortez and Rodrigues (2009), Kehl (2004) and others, in order to support the reading we now propose.
\end{abstract}

Keywords: Poetesses of Paraíba; Contemporary Literature; Yolanda Queiroga de Assis.

\section{PALAVRAS INICIAIS}

\footnotetext{
1 Este trabalho é fruto de uma pesquisa de Iniciação Científica intitulada "Vozes femininas da poesia lírica na Paraíba" (SOUZA; ALVES, 2013).

2 Mestrando no Programa de Pós-graduação em Literatura e Interculturalidade, da Universidade Estadual da Paraíba, campus I. Graduado em Letras (língua portuguesa) pela Universidade Federal de Campina Grande, campus I. E-mail: <olavo.barreto@live.com>.

${ }^{3}$ Pós-doutor em Literatura Brasileira pela UFMG. Professor de Literatura Brasileira e Teoria Literária na UFCG, Campus de Campina Grande. Email: <helderpin@uol.com.br>.
} 
A poesia paraibana, como qualquer outra poesia - uma vez que o texto poético transcende rótulos geográficos, mas aqui usamos o termo para distinguir e situar os autores no âmbito da literatura nacional -, possui uma diversidade de autores que se expressam com particularidades temáticas diversas. Todo escritor traz para o texto literário a experiência de humanidade, qualificando nela seus simbolismos e sutilezas que dignificam o trabalho com a linguagem de forma a torná-la poética. Yolanda Queiroga de Assis, como uma escritora paraibana, ciente da sua função como agente artística, trabalha a estética literária da poesia, em um campo mais formal - utilizando, sobretudo gêneros clássicos como o soneto. Desse modo, este trabalho está constituído de modo a dispor elementos consideráveis para propormos uma leitura de seus escritos, observando, sobretudo, a veia estética que esta autora possui pela temática do ressentimento.

Na leitura que propomos acerca da poesia de Yolanda, além da observação dos elementos próprios do estudo analítico do poema (CORTEZ; RODRIGUES, 2009), pelo campo formal e estético, dialogamos com algumas considerações sobre o ressentimento como um tema de estudo na psicanálise. Para tanto, a psicanalista Kehl (2004) nos apresenta o conceito desta categoria de comportamento humano observado na prática cotidiana. Elemento que pode ser verificado em alguns poemas da autora que ora propomos análise.

O ressentimento é acompanhado por uma cosmovisão negativista da realidade. Para tanto, trouxemos neste trabalho algumas considerações de leitura acerca do pensamento de Schopenhauer (1995) propostos por Monteiro (2011) que demonstram ponderações sobre "a vida como sofrimento e dor", lugar privilegiado para o pessimismo e para a tristeza. Na visão do eu-lírico, em alguns poemas da autora, há manifestação da tristeza pela perda da saúde, da plena felicidade dos tempos de juventude; tendo no fim da vida um espaço o rememorar esses fatos com um sentimento de que não há mais um meio de vivenciar a docilidade da qual gozam os jovens, sendo a velhice o âmago das dores e da indiferença pela vitalidade.

Por fim, nas considerações finais, fazemos um contraponto entre o projeto estético de Yolanda Queiroga de Assis e algumas considerações críticas que fazem juízo de valor negativo à poesia da autora. 


\section{YOLANDA QUEIROGA DE ASSIS: UMA POÉTICA SOB A ÉGIDE DA TRISTEZA E DO RESSENTIMENTO}

\subsection{PERFIL BIOGRÁFICO}

Paraibana, natural de Pombal - sertão da Paraíba, membra associada da Academia Paraibana de Poesia, é uma das mais prolíficas autoras em atuação no cenário literário do deste estado. Seus livros, em grande maioria, saíram publicados pela editora Ideia (João Pessoa/PB) e somam o número de 18 obras. São elas: Psicose (1987), Árvore Cortada (1988), Espectros (1990), Estepe (1991), Fantasmas Dispersos (1989), Fiapos de minha vida (s/d), Encruzilhada de Emoções (1993), Feixe Desfeito (1995), Soprar dos Ventos (1996), Sombras (1998), Palco do Meu Eu (1998), Disfarces do Destino (1998), Flor sem Haste (1999), Eu em Mim (2001), Sonhos do Destino (s/d), Visões (s/d), Recortes da Alma (2006), Ventania e Momentos (s/d).

$\mathrm{Na}$ carreira como poetisa, recebeu inúmeros prêmios literários e condecorações que dignificaram seu estado de produtora de conteúdo literário. Dentre os organismos que promoveram tais honrarias estão o Clube Literário de Brasília e a própria Academia Paraibana de Poesia, da qual faz parte. No campo da arte, além o trabalho com a literatura, a poetisa é desenhista e pintora. A propósito disso, algumas capas de seus livros recebem ilustração composta pelas suas próprias mãos.

Observando as associações ao qual a autora faz parte, além da já citada academia de poesia, encontramos também filiação da poetisa à União Brasileira de Escritores UBE e à Associação Paraibana de Imprensa.

\subsection{APRECIAÇÃO SUMÁRIA SOBRE A OBRA POÉTICA DE YOLANDA QUEIROGA DE ASSIS}

Versejar sobre temas melancólicos é uma atividade recorrente na literatura brasileira. Na poesia, observando autores do romantismo em sua segunda fase obtemos versos de vasto grau de expressão mórbida. Sobre isso temos Álvares de Azevedo, como seus poemas Se eu morresse amanhã ou Adeus, meus sonhos!. Poemas que revelam um profundo sentimento de finitude, versejando sobre a morte como amiga e desejada, 
elevação plena da morbidez. Esta expressividade temática, contemplando a tristeza, o ressentimento num ideal doentio, é observada também na obra de Augusto dos Anjos, poeta paraibano de grande prestígio, do qual Yolanda Queiroga devota sua expressão. Sobre este autor observamos muitas citações em seus poemas de elementos do mundo obscuro. Vale rememorar o soneto Psicologia de um vencido que o eu lírico se delega um monstro, doentio, em estado propício à finitude da existência. Yolanda, de maneira particular, comunga dessa expressividade poética constitutiva da tradição literária da literatura brasileira do que diz respeito ao apreço pelo obscuro.

Carlos Nejar (2011), em sua História da Literatura Brasileira: da carta de caminha aos contemporâneos, declara que a obra de Augusto dos Anjos se expressa por "uma morbidez que o empurra para o polo inclinado e sombrio da existência" (NEJAR, 2011, p. 235); citação bastante profícua em significado para a poesia deste autor. Observando esta ponderação do poeta e crítico literário da Academia Brasileira de Letras sobre o referido poeta paraibano, cremos que esta declaração, embora específica, dignificada a alguém que já possui certo respaldo crítico no meio acadêmico, ela pode ser declarada para outras situações, observando a poética de outros autores que se expressam de forma parecida ao engenho estético do qual Augusto dos Anjos e Álvares de Azevedo podem formar grupo. Yolanda Queiroga, com sua escrita carregada de murmúrios revela-se como parte integrante de uma veia de expressividade que constitui a composição geral da poesia brasileira.

Bastos (2012) ao traçar um estudo analítico da periodização literária ressaltando a criação poética dos autores brasileiros, no capítulo sobre o Romantismo, declara a morte como um elemento fundante da expressão de muitos dos autores desse já referido estilo de época. O elemento citado, dentro do arcabouço da poesia romântica, compõe as nuanças temáticas que estabelecem a caracterização do escapismo - elemento que somado com os outros próprios do Romantismo dão forma a esse estilo de criação literária. Tal escapismo se configura, segundo o autor, pela "insatisfação do poeta romântico com a realidade à sua volta, resolve-se, na maioria das vezes, pela adoção de uma atitude de fuga, de evasão [...]" (BASTOS, 2012, p. 46). Esta insatisfação se dá pelo conflito do sujeito com o mundo. Uma vez este conflito estabelecido, insurge-se o eu lírico se expressando por um viés dionisíaco, contemplando na sua criação a morbidez e o pessimismo. Deve-se compreender que o estilo de época, embora isolado por muitas 
compreensões como "soluções linguísticas empregadas por grupos sociais em determinado lapso de tempo" (MOISÉS, 2004, p. 169), sua constituição está associada à reunião de estilos individuais de autores que corroboram uma dada escola literária.

Desse modo, o geral de características de um estilo de época se estabelece através da contribuição individual de um autor, com uma dada cosmovisão, que pode ser observada de um ponto de vista historiográfico, particularizando a cronologia de sua existência. Ou ressaltando a compreensão de mundo que particulariza sua experiência com a criação literária, sem a interferência de uma data específica. Com efeito, verificamos, diante do exposto, que de forma ampla, a poética de Yolanda Queiroga de Assis se vincula a uma compreensão de mundo pessimista, tal quais os poetas ultrarromânticos brasileiros, se promulgando através, sobretudo, de um escapismo. Do seu modo particular, Yolanda contempla o estado de vida da velhice como a motivação principal para a morbidez de seus versos. Não podemos neste estudo rotular a autora em um único estilo de época, uma vez que o Romantismo quando se estabelece como uma escola literária que, para tanto, nesse processo, existem influências externas ao movimento que conduzem a tal expressividade artística. Yolanda, como autora contemporânea, configura-se de forma proporcional, nalguns dos seus poemas, a aspectos do escapismo relatado por Bastos (op. cit.). Este único aspecto, restrito, contemplado em uma parte de sua produção, revela o estilo particular de sua manifestação poética. Vale salientar que a autora caminha por outras nuanças temáticas, dentre as quais estão à relação entre Deus e o homem, sob uma compreensão cristã de divindade, enfatizando, sobretudo, o discurso da súplica; a experiência da maternidade; dentre outras formas de discurso. Podemos observar a diversidade de temas na autora, principalmente através das suas trovas. Sobre isso, consideramos a existência dessa variedade, sobretudo, em dois livros, dos quatro que tivemos acesso nesta pesquisa: Palco do meи eu (1998) e Recortes da alma (2006).

No primeiro livro, construído apenas por trovas, uma leitura atenta de seus versos levará o leitor a conhecer a vertente expressiva da autora pela contemplação do cotidiano, bem como os temas melancólicos, versos circunstanciais e laudatórios às pessoas próximas da autora. No segundo livro citado, observa-se, em sua parte final, mais exemplares dessa diversidade temática. Nesse livro, em especial, as trovas são acompanhadas de palavras-chave que facilitam uma busca por versos que compunham 
temas propostos pela autora. Em meio a esses estão: família, carnaval, saudade, trabalho, etc.

Fazendo uma associação da autora em estudo e outros autores da poesia brasileira, encontramos em sua obra poética alguns fragmentos que emergem sua associação à veia estética de uma poesia da obscuridade. Sobre isso, encontramos poemas laudatórios ao seu mestre dor e pessimismo, Augusto dos Anjos:

\section{Eu... Tu... os versos teus...}

Tu, Augusto dos Anjos, poeta da morte, No teu pessimismo, totalmente imerso, Assim rezaste num empolgante verso:

"Ah! um urubu pousou na minha sorte".

Hoje vislumbro como vislumbraste tu, O mistério atroz que encobre minha vida. E sinto, como sentiste, a alma dolorida: Vejo em minha sorte também um urubu.

Teus versos penetram a estrutura Mais recôndita do meu triste coração, Contaminaram-me com sua desolação, Intensificaram minha desventura.

Contudo, eu os amo como se fossem meus. Contemplo-os, noite e dia, com todo o meu amor. Neles me inspiro e choro também minha dor, Querendo só, meus versos e os versos teus.

(ASSIS, 1987, p 25)

O poema foi extraído de sua obra de estreia Psicose (1987) e configura uma espécie de poema profissão de fé e laudatório. Ao passo que o eu lírico louva os versos de Augusto dos Anjos, confia a si esta expressão como sua verdade poética: "Neles me inspiro e choro também minha dor, / Querendo só, meus versos e os versos teus.”.

Observamos que neste poema, construído por quatro quadras, há menção a um verso do poema "Budismo moderno", da obra Eu e outras poesias (1919), de Augusto do Anjos. Este texto, de tom bastante pessimista, inicia-se com a declaração de desprezo. 
pela vida: "Tome, Dr., esta tesoura, e... corte / Minha singularíssima pessoa.”. O desejo voluptuoso pela morte, diante da insignificância do sujeito, representada pelas “diatomáceas", uma espécie de micro algas, revelará a insatisfação com momento vivido pela exclamação do eu lírico: “Ah! Um urubu posou na minha sorte!”. A menção desta ave de rapina no poema indica a grande densidade projetada na experiência do eu lírico. As aves de rapinas constituem sua alimentação com refeições repletas de carne, e no caso especial do urubu, carne em estado de putrefação. O poema tem por penúltimos versos:

"Dissolva-se, portanto, minha vida / Igualmente a uma célula caída / Na aberração de um óvulo infecundo;". Versos de intensa demonstração de morbidez e pessimismo. Nesta citação o símbolo do "óvulo infecundo" declara a quebra do ciclo da vida, que em sua gênese já está fadada ao fracasso.

É neste espírito de obscuridade que Yolanda repousa seu discurso poético. O desejo pela intensidade de abatimento do espírito, apresentando de forma singular na obra do autor paraibano, ressurge na poesia da poetisa com a mesma força que toma cada rima posta nos seus poemas. Como podemos perceber nestas palavras: "Teus versos penetram a estrutura / Mais recôndita do meu triste coração, / Contaminaram-me com sua desolação, / Intensificaram minha desventura.”. Assim, a poesia de Augusto dos Anjos se mostra como o alimento que fortifica a criação poética da autora.

É bastante vasto o número de textos da poetisa que refletem sobre a criação poética, focalizando o obscuro. Em Palco do mеи еи (ASSIS, 1998, p.41), declara a poetisa:

Eu tenho no coração

Uma fonte de fervor,

De carinho e devoção

E também de grande dor.

Observa-se que a entre a publicação de Psicose, primeiro livro da autora, e do livro que contém a trova citada acima se configuram 11 anos. Sobre esta ponderação, poderemos afirmar, possivelmente, que a produção poética da autora possui certa coesão no seu discurso. Ainda sobre esta consideração, observamos, dentre outros poemas, na sua obra mais recente, ao qual tivemos acesso, a seguinte trova:

\section{Desengano}




\author{
Vejo com melancolia a \\ vastidão do oceano... \\ Porém uma nostalgia \\ aumenta meu desengano.
}

(ASSIS, 2006, p. 149)

A trova traz a visualização do oceano sob um olhar melancólico. Um sentimento que traz o passado e que faz crescer a veia triste do eu lírico de Yolanda Queiroga, sempre demonstrando amarguras quando se contempla o mundo. E neste olhar, o mundo, o fazer poético, para autora, sempre se revelará com a tristeza da alma:

\author{
Gosto de fazer poema \\ para exprimir minha incerteza, \\ tenho somente por tema \\ meus momentos de tristeza.
}

(ASSIS, 1998, p. 40)

O gesto que a poetisa traça nesta trova designa como a sua produção poética se dá. É através da incerteza, daquilo que não está divisado, daquilo que busca uma definição que surge a inspiração, a força para a criação do verso. Este incômodo, que o eu lírico trata, representa as incursões que o mundo impõe ao sujeito. A poesia imprime, em sua composição, a experiência do homem, com suas emoções específicas, seu sentimento de pertença ao mundo, seja glorificando o que há nele ou refutando. Sobre essa relação entre a emoção no poema e a vivência do sujeito, Cortez e Rodrigues (2009) nos declaram:

Essa emoção, é certo, alimenta-se de algum modo na realidade, que é, afinal, resultado de institucionalizações, de ideias. [...] A mensagem poética, embora possa conter um fato (ou fatos narrativos), busca ainda, às vezes mais do que outra coisa, acionar estados, vivências, ideias, sutilezas. (CORTEZ; RODRIGUES, 2009, p. 59).

Com efeito, podemos compreender que a poesia é fruto das circunstâncias da qual a alma do poeta vivencia. A poesia se alimenta da realidade, inscrevendo no seu estabelecimento um meio de instigar o leitor a sentir no corpo do texto elementos que podem levá-lo a experimentar as mais diversas formas de expressão do sentimento humano. No discurso poético de Yolanda Queiroga, compreendemos que a experiência do ressentimento, principalmente quando se trata do tempo da velhice, não como um mal que se viveu e se escreveu, mas como uma abstração, qualifica a poesia da autora como fruto da vivência do sujeito no mundo. 
Como pode se perceber, pelos poemas apresentados neste estudo, a poesia de Yolanda se constitui de construções clássicas no ponto de vista formal. O uso da trova, como visto anteriormente, já revela a propensão da autora pelas formas clássicas de construção poética. É observável, ao longo de sua obra, uma vastidão de sonetos, forma consagrada por muitos autores, inclusive por Augusto dos Anjos e Álvares de Azevedo, autores que, assim como Yolanda, primaram pelo verso metrificado, bem como, em alguns momentos de suas escritas, por tematizações mórbidas.

No prefácio de Recortes da Alma, a poetisa paraibana, Maria do Socorro Cardoso Xavier, ao apresentar a obra de Yolanda, refere-se a esta, sobre seu debruçar nas formas consagradas da poesia: "Cada construção poética, predominantemente clássica, pois prefere o soneto, a sextilha, o quarteto e terceto, também exímia trovadora.” (XAVIER,

2006, p. 12). E isto pode ser verificado em todos os seus livros. É inúmera a quantidades de sonetos, que tomam as páginas de Árvore cortada (1988) e Psicose. Além do seu livro só se trovas Palco do теu eu.

\subsection{PONDERAÇÕES ACERCA DE ALGUNS POEMAS DE YOLANDA QUEIROGA DE ASSIS}

Como visto anteriormente, a poética da autora, em estudo, se expressa com elementos que configuram um ideal mórbido, triste e pessimista. Para aprofundar mais a leitura que ora propomos neste texto, selecionamos três poemas seus que representam de forma significativa este discurso de obscuridade. Procuramos, nesta seleção, oferecer uma visão diacrônica de sua produção, uma vez que, dentre os poemas selecionados, elencamos textos do seu primeiro livro publicado - Psicose - até o seu mais recente livro, ao qual tivemos acesso - Recortes da Alma. Iniciamos nossa análise com o poema abaixo:

\section{Quero dormir}

Quero dormir, vasar num sono profundo

A tristeza que me ofereceu este mundo.

Quero deslembrar que é muito grande o meu mal

E que o bem é pequeno, efêmero, anormal.

Quero, num sono febril de moribundo,

Desligar me deste mundo imundo. 
Quero perder meu sentido funcional

Num sono perpétuo, sem retorno, irreal.

Quero dormir embrenhada no mal fatal,

De ser humana, amar e padecer em vão

Por um mundo que me nega cada ilusão.

Quero dormir um sono etéreo, uno, eternal,

Um sono que paralise-me os sentidos,

E cale em mim todos os sonhos perdidos.

(ASSIS, 1987, p. 43)

No poema, em uma atitude de afastamento do mundo real, o eu lírico almeja o ambiente do sono como refúgio para a alma sofrida pelas intempéries da realidade. Observe-se que não é um sono qualquer, mas um que leve o sujeito às profundezas. Esse desejo que indica uma intensidade, sobremaneira, pelo espaço do repouso conota um sentimento de profunda desaprovação pela realidade, uma vez que no sono a racionalidade está liberta de qualquer amarra condicionante do agir e do pensar racional. O sono, pela sua natureza, qualifica uma ação de quase nulidade do sujeito. Aquele que dorme está fora da realidade que o cerca; e no poema, este ambiente traz consigo um ideal de fortaleza.

Nos versos - "Quero deslembrar que é muito grande o meu mal / E que o bem é pequeno, efêmero, anormal."- encontramos uma menção que revela o conteúdo do pensamento maniqueísta, que segundo Abbagnano (2007, p. 641), “(...) admite dois princípios: um bem, ou princípio da luz, e outro do mal, ou princípio das trevas.". A luta entre o bem e o mal, neste fragmento, conserva-se por uma ideia que eleva o mal sobre o bem, e, desse modo, o bem vencido, o eu lírico deseja anular sua expressão ao ponto de indicar no trecho o ato do deslembrar. O esquecimento das mágoas que o mal traz, que enche a existência do eu lírico, configura-se um lenitivo, um alívio para um sujeito marcado pelas dores do mundo: "A tristeza que me ofereceu este mundo".

Vale lembrar que o sono profundo também metaforiza a morte. E este elemento também pode ser considerado um meio de se achegar à libertação. É no último suspiro da vida que homem encontra sua paz. No pensamento maniqueísta, separar-se do corpo representa a expressão máxima de libertação. A alma, para este pensamento, é interpretada como um ser de luz que traz consigo o conteúdo do bem; enquanto o corpo, 
com suas volúpias e propensões para dor, imprime a essência do mal. É preciso expurgar a essência do mal, para que a luz sobrevenha sobre o ser (ABBAGNANO, op. cit.). No poema, esta compreensão pode ser observada no verso: "Quero dormir um sono etéreo, uno, eternal, / Um sono que paralise-me os sentidos, / E cale em mim todos os sonhos perdidos.". O "sono etéreo" qualifica a ideia de morte, uma vez que a substância "éter", da qual formou a adjetivação da palavra sono é usada, sobretudo, para a conservação de cadáveres. A morte pare este eu lírico, ainda traz consigo uma entrega total de sua capacidade de ser no mundo. O silêncio, que cerca o ambiente do sono, alega a anulação dos ideais da voz do poema, que calada não pode mais sonhar, e sem sonho prefere não mais existir: "E cale em mim todos os sonhos perdidos.".

O sono nesse poema, além do ideal de morte - que além dos versos citados anteriormente, podemos evidenciar isso no trecho "Quero perder meu sentido funcional /

Num sono perpétuo, sem retorno, irreal". - sugere outra adjetivação bastante expressiva no poema: “Quero, num sono febril de moribundo, / Desligar me deste mundo imundo.”.

Aqui, temos a indicação do desejo, por parte do eu lírico, de um sono que se configura com um frenesi onírico. Pelo estado de fragilidade física e psicológica que um moribundo pode sem entontar, sendo que este sujeito está a vésperas de falecer, a razão não o mais acompanha. O seu sentido, naquele memento de sofrer, está amalgamado por um intenso fluxo de sensações que não possuem ordem racional. É neste estado de grande efervescência psíquica que o eu lírico deseja se consumir. Como "os sonhos perdidos" lhe são negados, o único momento de liberdade no sonhar é no momento onírico que marca a passagem do ser moribundo para a inércia da existência.

Esta ambiência que envolve uma atmosfera de obscura e neurótica perpassa todo o livro que contém o poema analisado. O poema que dá título ao livro encerra com os seguintes versos:

Cada poesia minha é uma neurose.

É um embrulho de infindas dores.

É ais, é soluços e é psicose

De florear angústia e dissabores.

(ASSIS, 1987, p. 24)

E assim, percebemos a vinculação da poetisa ao discurso do obscurantismo, assim como a expressividade do poeta Augusto dos Anjos. O dessabor é a alma da 
poesia de Yolanda. Na nossa experiência de leitura com esta poetisa, nos lembramos muito do pensamento do também filósofo pessimista, Arthur Schopenhauer. Assim, conforme afirma Monteiro (2011, p. 45), ao comentar a obra do filósofo alemão, “(...) a essência da vida é a dor."; ou pelas palavras do próprio filósofo: "Se a nossa existência não tem por fim imediato a dor, pode dizer-se que não tem razão alguma de ser no mundo." (SCHOPENHAUER, 1955, s/p). Diferente ao filósofo, a poetisa em estudo é inconformada com a dor. Mas a aproximação entre a literatura e a filosofia se dá pela apreciação que ambos dão ao que é "negativo". Para o filósofo, o sentido do viver subsiste na dor, enquanto a poetisa, no seu versejar, a nega todo momento, preferindo a morte como lenitiva, como no exemplo de soneto que trouxemos anteriormente.

Outro aspecto que consideramos importante na leitura que fizemos da poetisa é sua disponibilidade em versejar com um tom de ressentimento. Verificamos isso, sobretudo, nos poemas que tratam da velhice. O lamento pelo que se passou, a felicidade que se esvaiu, as forças corporais que não são mais as mesmas, configuram um corpo marcado pelo tempo. O conceito de ressentimento que ora compreendemos, é bastante lúcido nas palavras da psicanalista Maria Rita Kehl (2004):

\footnotetext{
Ressentir-se significa atribuir a um outro a responsabilidade pelo que nos faz sofrer. Um outro a quem delegamos, em um momento anterior, o poder de decidir por nós, de modo a poder culpá-lo do que venha a fracassar. (...) Para que ele [o ressentimento] se instale, é preciso que a vítima não se sinta à altura de responder ao agressor; que se sinta fraca, ou inferior a ele. (KEHL, 2004, p. 11 e 14).
}

Este outro, ao qual a psicanalista refere-se, não existe referente pleno na poesia de Yolanda. Os malogros que circundam a poesia desta autora, possivelmente ocorrem pela sua luta conta o tempo. Não podemos apontar isso de forma estrita nos poemas, mesmo levando em consideração os poemas que tratam da velhice, pois não existe o referente direto, mas sim o seu aspecto de abstração, é pelo não-dito que chegamos a essa percepção. O poema abaixo trata da "felicidade" como tema, focalizando, por fim, a passagem para a velhice como um tempo de lamentações pelo não vivido.

\section{A felicidade}

Eu passei a vida inteira

Buscando a felicidade.

E ela, na realidade,

Era bela e passageira. 
Sentada perto de mim,

Acenava-me a cada hora...

E eu, quase sempre por fora,

Só olhava para o fim.

Entanto não a senti,

Fui amarga e pessimista.

Quase enferma ou derrotista,

Não a vi, nem pressenti.

Enchi-me de nostalgia,

Sem vê o que a vida tem...

Com já o disse alguém:

"Era feliz e não sabia!"

Penso que a felicidade

Rastejou-me lado a lado,

Apontando em gesto alado,

Esperança e alacridade.

Nada, porém, enxerguei,

A velhice enfim chegou...

Tanta coisa perpassou.

Saudosista eu me tornei!

(ASSIS, 2006, p. 97)

Nas duas últimas estrofes, percebemos afirmações que delegam o caráter do ressentimento. Embora a culpa seja declarada pelo eu lírico é como se o sujeito do hoje não aceitasse como estava constituído o sujeito do ontem, indiferente a felicidade. Com uma alma que não contemplava o pedestre momento do "presente", preferindo as incertezas de um futuro, de um "fim", como escreve o eu lírico: "E eu, quase sempre por fora,/ Só olhava para o fim.”. Com este sentimento, como afirma o último verso do poema, o tempo da velhice se torna o lugar da saudade da juventude.

Além deste texto, outros vários circundam a obra desta poetisa. A ideia de fragilidade, de pequenez diante do agressor, ao qual fazemos ideia abstrata que seja o tempo, se revela significantemente no poema abaixo:

\section{Senescência}

É tão triste para o humano 
O chegar da senescência.

Traz melancolia e engano

E aniquila a existência.

O perpassar de cada ano, Ao velho dá decadência...

Rugas vis ou desengano

Afundam e dão falência.

A própria identidade

Já não tem mais validade,

Tudo acaba e vai ao chão.

E dói até quando alguém,

Com alguma ajuda provém,

Só por comiseração.

(ASSIS, 2006, p. 113)

O soneto construído sob o título de Senescência trata da tristeza pela chegada da velhice. Os versos finais do poema trabalham um ato que revela a debilidade do sujeito senescente. Sendo este não mais dono de suas atitudes, é preciso que outro ser venha em seu socorro para lhe auxiliar nos serviços diversos: "E dói até quando alguém, / Com alguma ajuda provém, / Só por comiseração.”.

É importante destacar neste poema o uso do vocabulário elevado. Termos como "senescência" e "comiseração" não são muito usuais na linguagem comum atual. Os temos podem ser considerados, por este motivo, arcaísmos. E dessa forma, contribuem para dar forma à estética do texto no cuidado em tratar da temática do envelhecimento humano.

\section{PALAVRAS FINAIS}

Como visto neste trabalho, a poesia de Yolanda Queiroga de Assis se estabelece, principalmente, pela expressividade melancólica, pessimista e ressentida, especialmente quando se focaliza o tema do envelhecimento. Versejando principalmente através das formas métricas consagradas do poema, a autora qualifica sua obra com um trabalho de cuidado na constituição de versos, nos parâmetros clássicos de estrofe, focalizando o soneto, como expressão mais evidente. De tal modo, conforme apresentado acima, a autora, embora 
sendo contemporânea, propõe sua obra com algumas nuanças próprias do ultrarromantismo.

Diante de sua obra prolífica, não observamos nenhum estudo crítico significativo sobre seus poemas. Na pesquisa prévia que fizemos, antes da construção deste texto, que sumariza alguns aspectos literários da obra da poesia estudada, encontramos apenas um ensaio do crítico literário paraibano Hildeberto Barbosa Filho intitulado "Odeio poesia" (2006). Nesse texto, o crítico apresenta obras de autores paraibanos que não possuem significância poética na construção dos seus textos. Segundo ele, a poesia, para ser de qualidade, precisa de um engenho criativo escrupuloso que conjugue na expressão o sentimento e a reflexão sobre os usos dos “códigos literários e movimentos do idioma". Na visão do crítico, Yolanda é uma poetisa menor por, simplesmente, seus textos se configurarem como "poesia-lágrima" ou "poesiasoluço" - um termo designado pelos poetas concretos Décio Pignatari, Haroldo de Campos e Augusto de Campos, que é conceituado por Filho (2006, s/p) como "a poesia dos que ingenuamente confundem poesia com confissão de sentimentos, com a expressão de mágoas, dores, alegrias, boas intenções, enfim, com os estados d'alma que trespassam a sensibilidade dos corações ditos românticos.”. Não cremos que a poesia de Yolanda seja menor por via disso, pois, como vimos, sua expressão consegue traduzir no poema reflexões de grande relevância de humanidade. Horácio, em sua Epístola aos Pisões, afirma que: "Não basta serem belos os poemas; tem de ser emocionantes, de conduzir os sentimentos do ouvinte onde quiserem." (HORÁCIO, 2005, p. 85). Se o leitor, ao ter contato com um poema, e consegue com ele se sentir motivado, tocado pelo discurso ali posto, este é o maior valor que a literatura pode oferecer. Os poemas da autora estudada, trazem aspectos da experiência humana, por uma compreensão pessimista. O valor de sua poesia, para nós, consiste nisto, transmutar em verso a dor alheia, um espelho próximo da realidade.

\section{REFERÊNCIAS}

ABBAGNANO, Nicola. Dicionário de filosofia. Tradução da $1^{a}$ edição brasileira coordenada e revista por Alfredo Bosi; revisão da tradução e tradução de novos textos Ivone Castilho Benedetti. $5^{\text {a }}$ ed. São Paulo: Martins Fontes, 2007.

ANJOS, Augusto dos. Eu e outras poesias. São Paulo: Martin Claret, 2005. [1919].

ASSIS, Yolanda Queiroga de. Recortes da Alma. João Pessoa: Ideia, 2006.

Palco do теи еи. João Pessoa: Ideia, 1998.

Árvore cortada. João Pessoa: Unigraf, 1988.

Psicose. João Pessoa: Unigraf, 1987. 
BASTOS, Alcmeno. Romantismo. In: de Janeiro: 7Letras, 2012.

Poesia brasileira e estilos de época. $3^{\mathrm{a}}$ ed. Rio

CORTEZ, Clarice Zamonaro; RODRIGUES, Milton Hermes. Operadores de leitura de poesia. In: BONICCI, Thomas; ZOLIN, Lúcia Osana. Teoria literária: abordagens históricas e tendências contemporâneas. $3^{\mathrm{a}}$ ed. rev. e ampl. Maringá: Eduem, 2009.

FILHO, Hideoberto Barbosa. Odeio poesia. Disponível em: <http://www.cronopios.com.br/site/artigos.asp?id=1568>, publicado em 14/07/2006 às 16h14min00, acessado em 14/04/2013.

HORÁCIO. Arte poética: Epístola aos Pisões. In: ARISTÓTELES; poética clássica. Trad. Jaime Bruna. 12ª ed. São Paulo: Cultrix, 2005.

; LONGUINO. A

NEJAR, Carlos. A singularidade: Augusto dos Anjos. In:

História da literatura brasileira: da Carta de Caminha aos contemporâneos. São Paulo: Leya, 2011.

MOISÉS, Massaud. Estilo. In: Dicionário de termos literários. $12^{\mathrm{a}}$ ed. rev. e ampl. São Paulo: Cultrix, 2004.

MONTEIRO, Fernando J.S. 10 lições sobre Schopenhauer. Petrópolis: Vozes, 2011.

SCHOPENHAUER, Arthur. Dores do mundo. Trad. Albino Forjaz de Sampaio. Salvador: Progresso, 1955.

SOUZA, Olavo Barreto de; ALVES, José Hélder Pinheiro. Vozes femininas da poesia lírica na Paraíba. Relatório final de pesquisa de Iniciação Científica (CNPq/UFCG, 2012-2013). Campina Grande: UFCG, 2013.

KEHL, Maria Rita. Ressentimento. São Paulo: Casa do Psicólogo, 2004.

XAVIER, Maria do Socorro Cardoso. Prefácio. In: ASSIS, Yolanda Queiroga de. Recortes da alma. João Pessoa: Idéia, 2006.

\section{Sites consultados}

Apolíneo e dionisíaco. Disponível em:

<http://www.edtl.com.pt/?option=com_mtree\&task=viewlink\&link_id=785\&Itemid=2>, acessado em 20/08/2013.

Obras de Yolanda Queiroga de Assis catalogadas pelo Instituto Histórico e Geográfico da Paraíba (IHGP). Disponível em:

<http://www.ihgp.net/biblioteca/index.php?item=12\&pagina=16>, acessado em 18/07/2013.

Currículo de Yolanda Queiroga de Assis para membra da Academia de Letras e Artes do Nordeste (ALANE). Disponível em:

$<$ http://alanepb.org/downloads/yolanda_curriculum.pdf>, acessado em 05/05/2013.

Recebido: 01.03.2015

Aceito: 10.06 .2015 